\title{
Transformações nas práticas narrativas audiovisuais na era pós-mídia
}

CHANGES IN AUDIOVISUAL NARRATIVE PRACTICES IN POST-MEDIA ERA

\section{Alita Villas Boas de Sá Rego}

Professora adjunta da Faculdade de Educação da Baixada Fluminense da Universidade Estadual do Rio de Janeiro.

E-mail: alitasa.rego@gmail.com

Recebido em 24 de agosto de 2015. Aprovado em 25 de janeiro de 2016.

\section{Resumo}

A proposta deste trabalho é investigar as diferenças nas práticas de produção, exibição e transmissão de vídeos comunitários pelos ativistas dos movimentos sociais no final dos anos 1980 e das transmissões via internet pelos midialivristas nas manifestações de rua realizadas em junho de 2013 no Rio de Janeiro. Vamos analisar de que forma elas se manifestam nas práticas comunicacionais alternativas e seus efeitos na subjetividade dos ativistas dos anos 1980 e dos midiativistas do início de século XXI.

Palavras-chave: Subjetividade. Pós-mídia. Midiativismo.

\section{Abstract}

The purpose of this study is to investigate the differences in the practices of production, display and transmission betweencommunity videos made by social movements activists in the late 1980s and internet transmissions made by the free media in the June 2013 street protests in Rio de Janeiro. We will analyze in which way they manifest themselves in alternative communication practices and how they affect the subjectivity of the activists from the 1980s and the activists of free media in the beginning of the 21 th century.

Keywords: Subjectivity. Post-media. Media activism. 


\section{Introdução}

A forma de distribuição da informação no modelo da Mídia Ninja ${ }^{1}$ utiliza o entrelaçamento das redes móveis com o computador para que qualquer um, possuindo uma câmera de vídeo ou fotográfica, ligada a um laptop ou a um telefone celular conectados à internet através de uma banda larga 4G, possa assumir o papel de narrador na primeira pessoa, apresentando suas próprias versões dos acontecimentos, sejam eles individuais ou coletivos. Ao contrário do jornalismo tradicional das grandes empresas de comunicação, nesse modelo não existe uma "verdade dos fatos" a ser veiculada por um transmissor produtor de significados e vários receptores passivos (broadcast), mas sim diversas micronarrativas sobre um mesmo acontecimento, realizadas por diferentes transmissores. O processo semântico cabe ao próprio receptor. Uma prática bastante diferente das realizadas pelos ativistas dos anos 1980, que pregavam a democratização das ondas do ar através das rádios e TVs livres e/ou piratas e das TVs de rua, que desejavam passar uma "mensagem" previamente produzida, fosse pelos produtores ou pela própria comunidade, após um processo de aprendizagem.

Considerando que o desenvolvimento das tecnologias de informação e comunicação e a convergência das mídias foram essenciais para a produção de uma subjetividade pós-mídia tal como escrita por Felix Guattari (1992), focaremos nas diferenças ocorridas na subjetividade dos militantes/ativistas que utilizam os meios de comunicação e seus efeitos práticos. E questionamos: o que é uma subjetividade pós-mídia? Quais são as principais diferenças entre as práticas dos militantes das mídias audiovisuais do século XX e as práticas midiativistas do século XXI? O uso das redes sociais e a posse dos meios de produção e a transmissão da informação audiovisual ao vivo democratizaram os meios de comunicação, ameaçando as formas de distribuição de informação tradicionais? Vamos tratar dessas questões a partir dos conceitos de Felix Guattari, Maurício Lazzarato, Gilles Deleuze, Hardt e Negri, aplicados a um estrato histórico delimitado.

\section{Práticas alternativas dos ativistas nos anos 1980-90: TV Pirata e TV de Rua}

1 A Mídia Ninja, formada em 2011 e que se declara uma alternativa à imprensa tradicional, tornou-se conhecida a partir das transmissões dos protestos ocorridos em 2013 no Rio de Janeiro. Apesar das críticas posteriores ao grupo Fora do Eixo (coletivo de origem da Mídia Ninja), realizada pelos outros coletivos e pelos meios de comunicação corporativos, foi a Mídia Ninja que ganhou mais visibilidade na cobertura dos acontecimentos. Por isso a utilizamos como exemplo de um novo modelo de transmissão, embora existam muitos outros grupos que fazem o mesmo. 
O uso da televisão pelos midiativistas das primeiras décadas do século XXI para distribuir informações alternativas às das mídias corporativas é bastante diferente das realizadas pelos militantes das últimas décadas do século XX. Os militantes da mídia das décadas de 1970-80 queriam fazer a "reforma agrária do ar", para que todos pudessem distribuir suas informações pelas ondas eletromagnéticas. Isso valia tanto para o rádio quanto para a $\mathrm{TV}^{2}$. Para denunciar a concentração da informação nas mãos das grandes corporações de comunicação, donas das concessões estatais, os ativistas tinham duas formas de atuação: a primeira, fazendo transmissões ao vivo através de TVs Livres ou Piratas $^{3}$, realizada com transmissores de baixa potência e com pequena abrangência, nos moldes das rádios piratas. A segunda, ligada aos movimentos sociais ${ }^{4}$, utilizava projeções de vídeos nas praças e ruas para ampliar a "conscientização" das classes mais populares através de um discurso ideológico de esquerda.

\section{A TV de Rua}

Desde 1982, com o surgimento do videocassete nacional, surgiram as primeiras práticas de apropriação do audiovisual pelos movimentos sociais. As características técnicas se adequavam à comunicação popular. A tecnologia permitia tanto a exibição de programas pré-gravados quanto a produção de mensagens originais criadas pela própria comunidade. Assim, também era importante capacitar as pessoas para a produção, distribuição e uso do equipamento. Em setembro de 1984, em São Bernardo do Campo, em São Paulo, aconteceu o primeiro encontro de grupos e entidades do país, para trocar experiências e realizarcursos de aperfeiçoamento. Foram feitas oficinas de trabalho onde eram apresentadas as

2 Nesse período, o espectro de transmissão televisiva comportava apenas 12 canais na faixa de frequência VHF, cuja utilização dependia (como ainda depende) de uma concessão do Estado.

3 A TV Livre de Sorocaba foi uma das primeiras a produzir atividades de transmissão pirata, realizando sua última transmissão na tarde do dia 12 de setembro de 1985. A TV Livre não sobreviveu às negociações oficiais para a criação de uma TV Comunitária, devido à falta de um movimento comunitário que desse suporte às reivindicações pela democratização da comunicação e à ação repressora do Departamento Nacional de Telecomunicações (Dentel), que suspendeu as atividades da emissora. No entanto a experiência provocou o debate nacional sobre a possibilidade de romper com o monopólio das comunicações através das transmissões clandestinas.

4 De acordo com Santoro (1989, p. 59), o termo "movimento popular" compreende "todas as formas de mobilização e organização das pessoas das classes populares, direta ou indiretamente vinculadas ao processo produtivo, tanto na cidade como no campo". Estão incluídos nessa categoria as ONGs, associações de bairro, clubes de mães, o MST, os grupos que lutam pela demarcação dos povos indígenas, os movimentos sindicais com caráter de classe etc. O objetivo da maior parte dos movimentos sociais nas décadas de 1980-1990 era o de esclarecer, conscientizar, emancipar e incentivar a participação política em territórios onde o Estado estava ausente ou não conseguia manter o controle. A comunicação popular no período incluía a publicação de jornais do tipo pasquins, boletins, folhetos, programas de rádio por alto-falantes e programas de exibição de vídeos nas praças da periferia. 
etapas técnicas do processo produtivo: operação de câmera, fotografia, sonorização, roteiro, edição, metodologia de exibição e básico operacional. Criou-se a Associação Brasileira de Vídeo no Movimento Popular (ABVMP), órgão centralizador que funcionava como representação política do grupo, capaz de buscar financiamento, organizar mostras e realizar cursos ou seminários. A ABVMP era a voz oficial nos debates em todo o país sobre a democratização dos meios de comunicação. Nesse contexto, surgiu a TV Maxambomba, criada pela ONG CECIP, o Centro de Criação de Imagem Popular. ${ }^{5}$ No início, a ONG atuava no âmbito das associações de moradores, com uma programação baseada em produção própria. Mas foi para as ruas da periferia do Rio de Janeiro em 1989, assim que comprou a sua "unidade móvel" de exibição: uma kombi equipada com um videocassete, um projetor, um equipamento de som e um telão (TOJA, 2010). Noale Toja (2010), uma das integrantes da equipe da TV Maxambomba, conta que o objetivo das exibições nas praças públicas da Baixada Fluminense era funcionar como "um dispositivo agregador, múltiplo e democrático", através dos vídeos que revelavam os modos de vida singulares da população da região. É claro que, se pensarmos a televisão em suas múltiplas definições ${ }^{6}$, tal como aponta Machado (2001), a TV Maxambomba está mais para uma exibição coletiva de vídeo sob a forma de um espetáculo de rua do que para uma emissora de televisão.

A programação começava com a definição dos locais de exibição. Precisava ser uma praça de fácil acesso, com infraestrutura de energia. Depois era realizado o contato com as lideranças sociais da região. A exibição em cada comunidade, com cerca de duas horas, era bimensal, por causa do tempo de produção dos programas. Sempre que o grupo chegava, havia uma chamada com o carro de som, anunciando a programação do dia. Ao cair da noite, montava-se a estrutura de som e a rádio Maxambomba convocava a população. Enquanto a exibição dos vídeos não começava, os microfones estavam à disposição para que as pessoas que fossem chegando pudessem dar recados, fazer convocações ou se apresentarem cantando, tocando ou entrevistando alguém.

Depois começava a projeção propriamente dita. Ao final, os microfones eram abertos novamente, para um debate sobre os vídeos exibidos. De acordo com Toja (2010), em alguns bairros as plateias podiam alcançar uma média de 400 a 500 pessoas. Entre 1993 e 1998, a Maxambomba procurou ampliar o conceito de TV comunitária, realizando oficinas de vídeo com experimentações através da produção participativa de vídeos populares.

5 O CECIP, fundado em 1986, é uma associação sem fins lucrativos que tem como objetivo a produção de informações e a criação de metodologias que contribuam para o fortalecimento da cidadania, influenciando políticas públicas promotoras de direitos fundamentais. Basicamente, sua produção está voltada para materiais educativos audiovisuais e impressos e para a realização de cursos e seminários.

6 A história do Canal 9 foi cheia de altos e baixos - principalmente de baixos. Nessa frequência funcionaram a TV Continental, TV Record, TV Corcovado, MTV e CNT. 
Ensinar a produzir significava também pensar sobre a maneira que consumimos TV, daí as oficinas desenvolviam o olhar crítico sobre a forma de ver tevê. Consequentemente, o vídeo é pensado como mais do que um aparato tecnológico de produção de imagem e som. A apropriação dessa linguagem está para além de ser um canal de transmissão de informação, mas sim um dispositivo de produção de subjetividade e de processos de singularização, que escapasse dos processos hegemônicos da mídia de massa. (TOJA, 2010, p. 47).

\section{A TV Pirata}

Em entrevista presencial, a historiadora e produtora de vídeo Elizabeth Formaggini (2013) relembra das ações dos ativistas na década de 1980. Funcionária do Museu de Imagem e Som (MIS), ela começou a participar das discussões sobre a democratização dos meios de comunicação ainda no final dos anos 1970, início dos 1980. Da discussão para a ação foi um passo e logo começou a participar do grupo que criou a rádio livre Frívola City, mais conhecida pelos órgãos repressores como uma rádio pirata. "A gente não estava preocupada com a qualidade formal e de conteúdo; para nós, do grupo, transmitir era uma ação política", conta ela. O grupo, anarquista, não tinha a hierarquia de chefes ou diretores. Elizabeth também participou da produção da TVento, TV pirata que realizava transmissões móveis a partir de um transmissor portátil de baixa potência e uma antena. Nesse caso, estava encarregada da divulgação dos dias, horas e locais das transmissões, e de providenciar o suporte jurídico para os ativistas que colocavam a TV no ar, caso fossem localizados e presos pelo Dentel, órgão encarregado do controle das ondas do ar. "A diferença entre a TVento e a TV Maxambomba era que nós fazíamos a transmissão nas ondas do ar como um ato de desobediência civil. A TV Maxambomba, como as outras TVs comunitárias ou TVs de rua, tinha que ser mais comportada, já que era uma ONG legalizada", relembra Elizabeth. As transmissões da TVento eram realizadas de uma kombi especialmente montada como um estúdio móvel de baixo alcance, que circulava pelos bairros e fazia suas transmissões em horários previamente divulgados na região. Os programas eram gravados previamente pelos ativistas e passavam na frequência do Canal $9^{7}$, interrompendo o sinal da emissora que tinha a concessão na época.

\section{Por uma subjetividade pós-mídia}

Embora na época da morte de Guattari, em 1992, o acesso à banda larga e a convergência das mídias ainda fosse incipiente, as atividades em busca de uma forma de transmitir informações de forma alternativa era uma prioridade para os ativistas da mídia.

\footnotetext{
$70 \frac{\text { Comunicação \& Inovação, PPGCOM/USCS }}{\text { v. 17, n. } 33 \text { (66-78) jan-abr } 2016}$
} 
O filósofo francês já previa que as redes rizomatizadas seriam capazes de produzir novas formas de vida, novos desejos, novas formas de pensar, agir e sentir. Uma outra vida, não mais calcada no regime de uma verdade transcendente, enunciada por máquinas que transmitiam no formato um-todos das mídias de massa, mas sim num regime semiótico em que a verdade fosse apenas um horizonte ${ }^{7}$. Essa era a subjetividade que surgiria com a convergência televisão/computador/redes móveis.

A junção da televisão, da telemática e da informática, que está se operando diante de nossos olhos, vai se completar, sem dúvida, na próxima década. A digitalização da imagem vai fazer com que a tela da televisão seja ao mesmo tempo a do computador e do receptor telemático. [...] O caráter de sugestão, até mesmo de hipnotismo, da relação atual com a televisão vai parar. Podemos esperar, a partir daí, que haverá um remanejamento do poder mass-midiático que se impõe à subjetividade contemporânea e uma entrada em uma era pós-mídia que consiste numa reapropriação individual coletiva e um uso interativo das máquinas de informação, comunicação, inteligência, arte e cultura. (GUATTARI, 1990).

O filósofo francês sempre se preocupou com o papel dos os meios de comunicação de massa na produção de subjetividade, com destaque para a televisão, com sua capacidade de sugestão e hipnotismo. Ele acreditava que, na era pós-midiática, haveria um remanejamento do poder a partir do desejo de apropriação individual, coletiva e interativa das máquinas de informação e comunicação. Uma consequência da subjetividade produzida pela soma das produções semióticas e semiológicas dos meios de comunicação de massa, da informática, dos dispositivos móveis, da convergência das mídias e do desenvolvimento dos dispositivos móveis como os telefones celulares, netbooks e tablets, além da Web 2.0.

Como define Guattari (1992, p. 14), a subjetividade produzida em um território existencial é a soma de máquinas sociais como a família, a escola, a religião, os esportes, o meio ambiente, as artes e as mercadorias culturais com as máquinas tecnológicas que operam na memória, na inteligência, na sensibilidade e nos afetos. A subjetividade é produzida polifônica e coletivamente, tanto a partir dos componentes semiológicos significantes quanto pela dimensão semiótica assignificante. Tanto pelos significantes e significados, conotações e denotações estudados pela semiologia quanto pela percepção estética dos signos, além dos produtos materiais e dos afetos. Podemos encontrar uma

7 Como aponta Blondeau em seu texto Become the media! Du post-media au médiascap, Guattari se apoia em Foucault, voltando-se para o estudo do regime de verdade no qual se insere a prática jornalística, em vez de procurar saber se algo é verdade ou não. Disponível em: <http://1libertaire.free.fr/ OBlondeau01.html> Acesso em: 10 jun. 2013. 
ressonância da dimensão semiótica assignificante no aforismo de McLuhan (1969) "o meio é a mensagem" da década de 1960. McLuhan dizia que a verdadeira mensagem dos meios de comunicação era a transformação provocada nos modos de pensar, agir e sentir.

A segunda geração de serviços online é responsável pela diversificação nas formas de publicação, pelo compartilhamento e organização da informação e pela ampliação dos espaços para a interação entre os usuários. Em Web 2.0: participação e vigilância na Era da Comunicação Distribuída, Antoun (2008) analisa o surgimento da Web 2.0 como o substituto do padrão das mídias de massa com suas mensagens redundantes, repetitivas e hipnóticas. Para ele, a nova mídia iria reverter a concentração da informação, característica das grandes redes globais de comunicação, transformando o consumidor em um usuário capaz de criar, produzir, editar, transmitir e controlar sua própria informação. Somando a Web 2.0 aos dispositivos móveis digitais, RHEINGOLD (2005) detectou que a comunicação instantânea promovida pela convergência das mídias deu origem a uma "multidão esperta" (smart mobs/foules intelligents). Uma geração que se utiliza das tecnologias de cooperação desenvolvidas a partir da internet para criar uma nova cultura alternativa, libertária e criativa, capaz de derrubar governos e ampliar exponencialmente a produção de informação/conhecimento. Unida pelo desejo de um mundo diferente, essa multidão foi para as ruas reivindicando mais democracia, mais emprego, mais saúde, mais liberdade. Em resumo, reivindicando uma nova forma de vida.

A primeira grande atuação do midiativismo global se deu no final de 1999, durante a reunião da Organização Mundial do Comércio (OMC) em Seattle, nos Estados Unidos. Antoun (2001) comenta que a grande mídia falada, impressa e televisiva divulgava que a manifestação era provocada pelos fazendeiros internacionais contra os subsídios americanos para os produtos agrícolas do país. Parecia uma luta econômica entre países soberanos que defendiam interesses locais. Mencionavam-se os protestos mas eles nunca eram vistos. Quem acompanhava a cobertura pelos grandes veículos não compreendia por que o prefeito de Seattle colocou a cidade em estado de emergência. Eles acreditavam que os protestos eram realizados por baderneiros internacionais, tal como era descrito pela agência de notícias da OMC. As imagens da violência eram distantes e impessoais e as afirmações eram confirmadas pelas entrevistas dos especialistas e pelas reportagens mediadas pelos repórteres. Os midiativistas agiam contra esse controle da informação, através da ação do Independent Midia Center (IMC) na internet. O IMC foi criado por organizações de ativistas que faziam a cobertura minuto a minuto da reunião da OMC, usando a tecnologia de edição aberta (open publishing). O Centro funcionava como um serviço de contrainformação, reunindo e disponibilizando o material colhido pelos próprios ativistas. A cobertura implicava na participação dos acontecimentos e dava origem 
a narrativas subjetivas de quem estava presente de corpo inteiro na luta e não pretendia trocar suas informações por dinheiro. Ali, o conhecimento não era mercadoria. Era um bem a ser compartilhado por todos, que podia ser distribuído sob a forma de copy left. A internet, nesse contexto, passou a ser uma "máquina de guerra" que funcionava como uma linha de fuga do circuito totalizante da organização midiática daquele momento.

Essa cobertura jornalística independente ameaça as formas de comunicação tradicionais no formato um-todos, já que a informação passava a ser produzida e transmitida a partir de um sistema de trocas rizomáticas entre emissores que estavam no mesmo plano. (BERARDI, 2006).

As redes rizomáticas contemporâneas são agenciamentos maquínicos que podem se apresentar, tanto como totalidades significantes - como os sites e "portais-currais" grandes organizações comunicativas ou afirmações pessoais de um sujeito que deseja afirmar sua identidade - quanto apontar para um corpo sem órgãos, que "não para de desfazer o organismo, de fazer passar e circular partículas assignificantes, intensidades puras" (DELEUZE E GUATTARI, 1995, p. 12), como acontece com as redes sociais virtuais.

Máquinas de guerra que fornecem as linhas de fuga para os ativistas contemporâneos em suas lutas moleculares, os rizomas informacionais são como as culturas de aipim, em que não existe um centro, já que cada bulbo se conecta ao outro através de hastes e fluxos subterrâneos. Sua multiplicidade de formas ameaça o modelo comunicacional tradicional no seu formato hierárquico centralizado, em que as emissoras geradoras de conteúdo ${ }^{9}$ negociam a programação e o uso da logomarca da emissora, originando as relações entre "cabeça de rede" e afiliadas que vão definir o conteúdo da programação televisiva.

De acordo com Blondeau (2004), o midiativismo transforma a internet em um "espaço de engajamento público, como espaço de configurações narrativas e dramáticas da palavra pública que se articula em forma de rede". Por isso, a nova máquina de guerra

8 Portais-currais procuram manter o usuário dentro dos seus limites, oferecendo todos os tipos de serviços/informações, remetendo sempre para os demais suportes, cujo conteúdo é produzido pela mesma organização. A produção verticalizada e horizontalizada dos enunciados midiáticos é a norma nas empresas de comunicação brasileiras, por isso a mesma informação está presente no rádio, na TV, no jornal, além das páginas do Facebook, Twiter e Orkut gerenciadas pela organização.

9 É importante não confundir os conceitos de geradora, retransmissora e repetidora com os conceitos de cabeça de rede e afiliadas, utilizados pelas emissoras em suas relações comerciais. Uma cabeça de rede, que é uma geradora, pode possuir relação contratual com outras várias geradoras e o objeto do contrato entre ambas é a marca e a programação que serão negociadas e não a possibilidade de produzir ou não conteúdos, um dos pontos centrais que diferencia geradoras de retransmissoras e repetidoras. BRASIL. Agência Nacional do Cinema. TV Aberta - Mapeamento. Estudo elaborado pela equipe da Superintendência de Acompanhamento de Mercado - SAM/ANCINE. 2010, 80 p. Disponível em: $<$ http://www.ancine.gov.br/media/SAM/Estudos/Mapeamento_TVAberta_Publicacao.pdf $>$ 
dos midiativistas não é isenta. Ela abre mão da verdade e busca a veracidade que vai se manifestar nas diferentes versões dos acontecimentos que vão convergir sobre os mesmos enfoques, mesmos temas. (ANTOUN, 2001).

Ao contrário dos anos 1980, quando os ativistas iam para as praças apresentar um conteúdo previamente editado - por conta das condições técnicas do período -, os movimentos sociais já possuem diversas ferramentas tecnológicas para fazer política. Iniciativas populares se apropriam das redes telemáticas para disseminar fotos, áudios e vídeos com o propósito de mobilizar a população para lutar por seus direitos. As consequências foram vistas nas manifestações do mês de junho de 2013 em todo o Brasil, que continuaram julho adentro. O poder em rede, tal como definido por Hardt e Negri (2005), ou o rizoma midiático, foi apropriado por pessoas singulares que não são ligadas a partidos e nem a movimentos sociais que buscam unificar as demandas populares em palavras de ordem. Ao contrário da massa ${ }^{10}$, que em sua homogeneidade disforme só consegue agir por meio de um líder, essas singularidades formam uma multidão que não se unifica enquanto um povo que dá sustentação a um Estado. "O povo é uno [...] sintetiza ou reduz essas diferenças sociais a uma identidade" (HARDT E NEGRI, 2005, p. 139). Só mesmo enquanto reduzido a uma unidade o povo pode ser governado. Já a multidão é ingovernável, na medida em que é formada por singularidades que não se reduzem a um denominador comum e que se mantêm na diferença radical: culturas, raças e etnias, gêneros, orientação sexual, formas de trabalho e desejos. Uma multiplicidade que só consegue se organizar porque é capaz de agir em comum. De acordo com Hardt e Negri (2005, p. 141), "a multidão é o único sujeito social capaz de realizar a democracia, ou seja, o governo de todos por todos".

É contra essa democracia popular que os meios de comunicação hegemônicos lutam. Por isso, sempre que ocorrem protestos em massa, como os que ocorreram no Brasil em julho de 2013, os meios de comunicação perguntam: o que vocês querem? E estão sempre em busca de um líder que responda por todos, capaz de unificar reivindicações que nunca se reduzem à unidade.

\section{Práticas alternativas dos midialivristas nos anos 2000}

10 De acordo com Blummer (1978), a massa não possui organização social, costumes e tradição, um corpo estabelecido de regras ou rituais, um conjunto organizado de sentimentos, nem qualquer estrutura de status-papéis ou liderança institucionalizadas. [...] É constituída por um agregado de indivíduos que se encontram separados, desligados, anônimos e, mesmo assim, formando um grupo homogêneo em termos de comportamento da massa, que, justamente por não resultar de regras ou expectativas preestabelecidas, é espontâneo, inato e elementar. (BLUMMER, 1978). 
É nesse contexto tecnológico que surge a Mídia Ninja, que ganhou fama nacional durante as manifestações de junho de 2013. No dia 17, no Brasil, os protestos da população foram transmitidos pela televisão e pelo streaming da internet. E a diferença foi flagrante: na TV comercial, as imagens eram capturadas do alto dos edifícios. Imagens distantes, de um ponto de vista externo. O áudio era o discurso dos jornalistas e dos analistas convidados. Manifestantes não falavam. Já a mídia livre fazia suas transmissões no meio dos acontecimentos. Bastava um telefone celular, um notebook e acesso à internet. A cobertura ao vivo apresentava imagens das ruas que as câmeras da TV Globo não mostravam. A polícia batendo nos manifestantes que corriam, bombas de gás lacrimogênio, balas de borracha, violência. Esse foi o tom da cobertura independente, formada por um coletivo midiativista que reunia pessoas de diversas partes do Brasil, que transmitem ao vivo no calor dos acontecimentos.

Os novos jornalistas fazem sucesso pela instantaneidade com que "postam as fotos e vídeos no momento em que as coisas acontecem". ${ }^{11}$ Foram os links no Twitter, no Facebook e em outras ferramentas de mídia social e das imagens postadas no YouTube que mostraram a verdadeira face das manifestações em todo o Brasil. Tal como no caso da cobertura do CMI em Seattle, ficou comprovado que a multidão que protestava por todo Brasil era mais do que uma manifestação de um grupo de baderneiros e que a polícia estava agindo de forma extremamente truculenta. O levantamento apresentado pelo site jornalístico BlueBus ${ }^{12}$ através do infográfico realizado pelas empresas iCustomer e Odiseu, sobre o monitoramento das mídias sociais entre 1 e 19 de junho, mostrou que, até o dia 24 de junho, 216 mil pessoas escreveram online sobre os protestos no Brasil. A convocação a partir do dia 13 pelo Facebook foi acompanhada pela cobertura via Twitter (65\% de posts) e pelas imagens do YouTube produzidas pelos telefones celulares de manifestantes e pelas equipes NINJA. O coletivo Narrativas Independentes, Jornalismo e Ação (NINJA) foi criado em 2013. O grupo pesquisa e experimenta práticas jornalísticas em diversas plataformas e ficou conhecido durante as manifestações a partir de junho de 2013.

No modelo de jornalismo NINJA, a equipe básica é formada por um cinegrafista e um fotógrafo. $\mathrm{O}$ cinegrafista transmite as manifestações ao vivo, construindo uma narrativa em primeira pessoa. O plano-sequência da câmera é como o olhar de um manifestante. As transmissões são publicadas simultaneamente no site da PósTV, que funciona como um

11 DE SÁ, N. Com protestos, web deixa TV para trás. Folha de S.Paulo, 02 jun. 2013. Disponível em: <http:// www.bluebus.com.br/com-protestos-web-deixa-tv-para-tras-nelson-de-sa-hoje-na-folha/>

12 ODISEO; ICUSTOMER. + de 200 milhoes impactados pelos protestos nas redes socs, infográfico exclusivo. Disponível em: $<\mathrm{http} / /$ www.bluebus.com.br/de-200-milhoes-impactados-pelos-protestos-nas-redes-sociais-veja-1-infografico/>/ 
agregador de diversas transmissões, permitindo que o usuário acompanhe diversos pontos de vista de um mesmo acontecimento. Já o fotógrafo fica próximo ao cinegrafista com o notebook, que possui duas funções: fazer o upload para o Facebook das fotos da cobertura e compartilhar a rede de internet com o smartphone do cinegrafista. Como no caso de grandes aglomerações as redes de internet móvel 4G ficam instáveis, o grupo NINJA mobiliza moradores a abrirem seus sinais de Wi-Fi permitindo que as transmissões aconteçam.

As transmissões iniciais, com uma webcam, eram realizadas via plataforma Ustream de vídeo. Mas desde que o serviço passou a exibir propagandas e que o sinal das transmissões de rua começou a cair constantemente, foi adotado o serviço de Twitcasting, uma ferramenta leve, sem propaganda e que aguenta a grande quantidade de webespectadores. Também, após experimentações individuais, compartilhadas entre o grupo, o NINJA adotou um smartphone $4 \mathrm{G}$ para as coberturas. As narrativas são publicadas de forma independente no Twitcasting.

O webespectador pode selecionar o link para o NINJA que está transmitindo no momento e do local que o interessa. Quem está assistindo envia comentários e perguntas e, não raro, até entra por skype e participa do papo. Algumas transmissões chegaram a ter cerca de 12 mil pessoas assistindo simultaneamente. Uma audiência maior do que muitas rádios $\mathrm{FM} \mathrm{e} \mathrm{AM}$, além de TVs por assinatura.

\section{Algumas considerações}

Quem acompanhou a cobertura das manifestações sociais brasileiras tanto via streaming online quanto pelos canais de televisão pôde verificar que as emissoras tradicionais interromperam as transmissões de manifestações ao vivo para voltar à programação do horário nobre. As informações que aparecem a partir daí são editadas e vinculadas só nos programas jornalísticos da grade. No entanto, aquele que fica conectado nas transmissões de streaming da PósTV, o braço audiovisual da Mídia Ninja, verifica que é na hora em que a TV aberta sai do ar que a polícia dá vazão a toda a sua truculência.

Os repórteres NINJA, com seus celulares e laptops, podem ser considerados como os efeitos primeiros de uma subjetividade pós-mídia, que não se contenta em ficar no sofá assistindo as informações mediadas pelos jornalistas tradicionais. Atualmente eles formam o novo grupo de midiativistas que, totalmente conectados, não aceitam mais a condição de emprestar sua voz para os aglomerados midiáticos. Com suas narrativas na primeira pessoa, com sua ação em vez da mediação, talvez sejam eles os primeiros a questionar os discursos universalizantes da mídia tradicional que redundam nas palavras de ordem da ideologia hegemônica. 
Verificar as diferentes narrativas na primeira pessoa disponibilizadas pelo Tweetcasting descortina o universo das narrativas verídicas pós-midiáticas, tal como foi descrito por Guattari (1992). Entre os novos ativistas, não vemos palavras de ordem da luta contra o controle da informação. Vemos essa luta na prática, possibilitada pela tecnologia digital, que barateia e facilita o uso de equipamentos e redes. Uma situação bastante diferente da encontrada pelos ativistas da metade final do século XX. Para estes, a luta contra o controle das informações, conhecimentos e afetos passava pela desconstrução do conteúdo ideológico dominante no nível da linguagem. Trocava-se uma narrativa pela outra, um regime de verdade por outro.

Para os midiativistas do século XXI, não se trata de uma luta contra-hegemônica dos procedimentos jornalísticos, em busca de uma nova verdade para os meios de comunicação. Não é uma luta por conteúdos. É por uma nova forma de vida, na qual o que está em jogo é a posse da tecnologia. Quem conhece, produz suas próprias linhas de fuga singulares na busca por novas formas de interação social e de colaboração. Isso pode ser verificado quando os repórteres NINJA pedem que as pessoas abram suas redes wireless para facilitar a transmissão da luta na rua.

Nesse caso, há uma concordância com Berardi (2006), quando este afirma que os meios alternativos não ameaçam a mídia tradicional, mas revelam-se como uma ameaça aos fundamentos da função jornalística, que sempre procurou ter o controle da "verdade dos fatos". É inegável que existe uma enorme desproporção de forças entre aqueles que detêm os meios de comunicação de massa e a multidão. É esse fato que valida as ações de luta pela democratização dos meios de comunicação pelos ativistas e midiativistas desde os anos 1970.

\section{Referências}

ANTOUN, H. Jornalismo e ativismo na hipermídia: em que se pode reconhecer a nova mídia. FAMECOS: mídia cultura e tecnologia, Porto Alegre, v. 1, n. 16. dez.. 2001. Disponível em: $\leq$ http://www. revistas.univerciencia.org/index.php/famecos/article/view/274/208>.

Web 2.0: Participação e Vigilância na Era da Comunicação Distribuída. Rio de Janeiro: Ed. Mauad, 2008.

BERARDI, F. Les radios libres et l'émergence d'une sensibilité post-médiatique. Multitudes. n. 21, verão 2005. Disponível em: <http://www.multitudes. net/Les-radios-libres-et-l-emergence-d $>$. Acesso em: 25 jun. 2006.

BLONDEAU, O. Become The Media! Du Post-Media au Médiascape. Colloque Internet, Culture and Society: French and American Prespectives. Austin, Université d'Austin. 2004. 
BLUMER, H. A massa, o público e a opinião pública. COHN, G. (Org.). Comunicação e Indústria Cultural. São Paulo: Cia. Editora Nacional, 1978.

DELEUZE, G.; GUATTARI, F. Mil platôs. Capitalismo e esquizofrenia. Rio de Janeiro: Editora 34, 1995. FERNANDES, L. Batalha na frente do Palácio da Guanabara. O Globo, Rio de Janeiro, 12 jul. 2013.

FORMAGGINI, E. Entrevista concedida à autora. 2013.

GUATTARI, F. Vers une ère post media, 1990. Chimeres, n. 28, primavera-verão 1996. Disponível em: $<$ http://www.revue-chimeres.fr/drupal_chimeres/files/28chi02.pdf> Acesso em: jun. 2013. Caosmose. Um novo paradigma estético. Rio de Janeiro: Editora 34, 1992.

HARDT, M.; NEGRI, A. Multidão: guerra e democracia na Era do Império. Rio de Janeiro: Ed. Record, 2005.

MACHADO, A. Rádios livres: reforma agrária do ar. São Paulo: Ed. Brasiliense, 1986. A televisão levada a sério. São Paulo: Ed. Senac, 2001.

MCLUHAN, M. O meio é a mensagem. [S.n], [1969?]

RHEINGOLD, H. Foules Intelligentes. La révolution qui commence. Paris: M2 Éditions, 2005.

SANTORO, L. F. A imagem nas mãos. O vídeo popular no Brasil. São Paulo: Summus, 1989. Disponível em: $<$ http://books.google.com.br/books?id=RX-6-FWQ-aMC\&printsec $=$ frontcover\&hl=pt-BR\#v=onepage \&q\&f=false> Acesso em: Jun 2013.

TOJA, N. TV Maxambomba: processos de singularização. 2010. 87 f. Dissertação de Mestrado. Programa de Pós-Graduação em Educação, Cultura e Comunicação, Universidade do Estado do Rio de Janeiro, Duque de Caxias, 2010. 